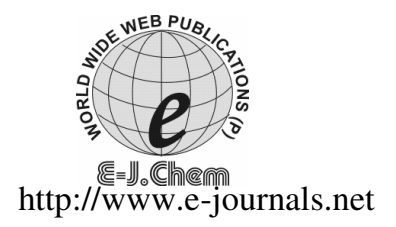

\title{
Study of Mechanical Properties of Waste Biomass Reinforced Urea-Resorcinol-Formaldehyde Composites
}

\author{
A. S. SINGHA ${ }^{*}$, B. S. KAITH ${ }^{\S}$, INDERJEET KAUR and \\ ASHWARYA JYOTI KHANNA ${ }^{\S}$ \\ National Institute of Technology, Hamirpur (H.P) -177 005, India \\ Himachal Pradesh University, Shimla (H.P)-171 005, India \\ assingha@gmail.com
}

Received 29 November 2008; Revised 5 April 2011, Accepted 9 April 2011

\begin{abstract}
Natural fibers play an important role in developing high performing fully biodegradable composites which will be a key material to solve the current ecological and environmental problems. Due to enormous advantages of composites reinforced with natural fibers, a study on pine needles reinforced urearesorcinol-formaldehyde composites has been made. Present investigation has revealed that urea-formaldehyde resin in 1.0: 2.5 ratio exhibits optimum mechanical behavior whereas in case urea-resorcinol- formaldehyde resin, the best mechanical behavior was shown by 1.0: 1.0: 2.5 ratios. However, reinforcing of this resin with pine-needles of $1 \mathrm{~cm}$ size and evaluation of their mechanical properties showed that mechanical properties increase with reinforcement. These results were further supported by the SEM and thermal studies.
\end{abstract}

Keywords: Composites, Reinforcements, Optimization, Mechanical properties, Thermal behavior

\section{Introduction}

In 1908, the first composite materials were applied for the fabrication of big quantities of sheets, tubes and pipes in electro-technical usage ${ }^{1}$ since before all resources for the production of commodities and technical products were derived from wood and natural fibers. Due to environmental problems, discarding method for glass fiber reinforced composites and their recycling has seriously been realized in the world ${ }^{2}$. Introduction of green composites will reduce the waste disposal problems especially in agricultural fields; environmental pollution etc. and can find various applications in engineering, electronic and automotive fields. Lightweight, low abrasiveness, absence of health hazard ness during processing, application and upon disposal etc. are the added advantages of the green composites $^{3-5}$. Researchers in different laboratories have studied the reinforcement of 
composites with different natural fibres such as flax, hemp, pineapple, pine needles, Saccaharum Ciliare, Hibiscus sadariffa, Grewia optiva, etc. ${ }^{6-9}$. India endowed with the abundant availability of natural fibers such as jute, coir, sisal, pineapple, ramie, bamboo, banana, pinus etc. has focused on the development of natural fibre composites to explore value added application avenues ${ }^{10,11}$. Today the renaissance of these materials as reinforcing fibres in technical applications is taking place mainly in automobile industry and for packaging purposes such as egg-cartons and fruit-cartons. Natural fibre reinforced composites could be used for the manufacturing of car parts, door panels etc $^{12,13}$.

Pine needles are the most common waste bio- product of pine trees found in the jungles of Himachal Pradesh. Our state H.P. is blessed with thick pine forests. Needles of Pinus roxburgii is the most common waste bio-mass found in jungles. These are the cause of fire hazards during summer season (shedding time of pine trees) causing air pollution and disturbing ecosystem (both flora and fauna). The literature review has revealed that a very little work has been done for the utilization of this huge natural wealth as reinforcing material in composites for preparing some industrial product. The production of these needles is 1 ton per hectare and this huge natural wealth is not exploited for better end products. Moreover, the mechanical strength of this fiber is more as compared to other fibers.

Keeping in view the easy availability and the abundance of this waste bio-mass, we have proposed to use these pine needles as reinforcing material for the preparation of U-R-F based composites. In this paper, synthesis of U-R-F resin and randomly oriented intimately mixed pine needles reinforced composites prepared by compression molding method has been reported. The effect of fiber volume on the mechanical properties such as tensile strength, compressive strength, flexural strength, wear resistance and hardness has been investigated. Fiber- matrix interaction was also analyzed by morphological (SEM) and thermal (TGA/DTA) data.

\section{Experimental}

Pine needles were washed with water and dried well in oven before use. Urea (Qualigens Chemicals Ltd), formaldehyde solution (Qualigens Chemicals Ltd.), Resorcinol (CDH) and sodium hydroxide (Qualigens Chemicals Ltd.) were used as received.

Weights of the samples were taken on Shimadzu make electronic balance (LIBROR AEG- 220), composites were prepared on compression molding machine (SANTECH INDIA LTD.), wear testing was done on Wear \& Friction Monitor (DUCOM- TR-20L), testing of samples for tensile, flexural and compressive strengths was done on computerized universal testing machine (HOUNSFIELD H25KS), impact strength was tested on impact testing machine (IZODE METHOD), hardness was tested on (Rockwell Hardness Testing Machine), SEM of the samples were taken on scanning electron microscope (LEO 435VP) and thermal studies were carried- out on thermal analyzer (PERKIN ELMER).

\section{Preparation of resins}

\section{Urea-formaldehyde resin}

Urea-formaldehyde resin was synthesized by the standard method developed in our applied chemistry research laboraory ${ }^{4}$.

\section{Preparation of urea - resorcinol - formaldehyde resin}

The optimized mole ratio of urea and formaldehyde was taken in tri-neck flask and then resorcinol in specific mole ratio was added to the reaction mixture and stirred till the clear solution was obtained then $50 \% \mathrm{NaOH}$ was immediately added drop wise till the $\mathrm{pH}$ of the 
solution was adjusted to 7.5. The reaction mixture was heated for about $2 \mathrm{~h}$ at 50-60 degree and then raises the temperature to 70 degree and further heated for $2 \mathrm{~h}$ till resinification. Then the mixture was allowed to stand at room temperature for $2 \mathrm{~h}$ and then cured at 100 degree in compression molding machine under pressure $\left(400 \mathrm{~kg} / \mathrm{cm}^{2}\right)$ for initial $10 \mathrm{~min}$.and then post cured at $120{ }^{\circ} \mathrm{C}$ overnight. The cured samples were then subjected to various mechanical, thermal and morphological studies.

\section{Preparation of composites}

Composites were prepared in URF with pine needles of $1 \mathrm{~cm}$ length. Fiber to resin ratio was firstly optimized by taking 10\%, 20\%, 30\%, $40 \%$ and $50 \%$ fiber in the matrix. Firstly thorough mixing of resin and fiber was done and then mixture was poured in to the mold of $150 \times 150 \times 10 \mathrm{~mm}$. The surfaces of mold were greased with oleic acid to avoid adhesion of the mixture and easy removal of the composite. The mold was then kept under pressure $\left(400 \mathrm{~kg} / \mathrm{cm}^{2}\right)$ and temperature of 120 degrees for initial 10 minutes.After degasification the samples were post cured at $130{ }^{\circ} \mathrm{C}$ for $12 \mathrm{~h}$.

\section{Mechanical properties of samples}

\section{Wear test}

The samples of $50 \mathrm{~mm}$ length were tested with loads varying from 1.0 to $3.0 \mathrm{~kg}$. For each load the machine was allowed to run for 15 minutes at the rate of $500 \mathrm{rpm}$ and the readings were recorded. After 15 minutes the sample was taken out from the machine and weighed. The loss in weight due to abrasion was calculated and this weight loss was used as the measure of wear. Each sample was tested for five times and their standard deviation was calculated and average of the readings was taken as the measure of wear.

\section{Tensile strength test}

The sample of $80 \mathrm{~mm}$ length was clamped in two jaws of the machine. Each end of the jaws covered $20 \mathrm{~mm}$ of the sample. Tensile strength was studied over the rest of $40 \mathrm{~mm}$ gauze length. Tensile stress was applied till the failure of the sample and load-extension curve was obtained. Each sample was tested for five times and standard deviation was calculated.

\section{Flexural strength test}

Flexural strength of the samples was measured on universal testing machine. A sample of $100 \mathrm{~mm}$ was placed on the edges and each edge covered the $20 \mathrm{~mm}$ of the sample. Strength was tested on the rest of $60 \mathrm{~mm}$ length according to ASTM D 790. Load has been applied till the failure of the sample. Each sample was tested for five times and their standard deviation was calculated.

\section{Compressive strength test}

The samples of length $40 \mathrm{~mm}$ was held between the two platforms. The compression stress was applied till the failure of sample. Total compression per unit force was noted. Compression test was also taken five times and standard deviation was calculated.

\section{Hardness and impact strength}

Hardness of the samples was tested on rockwell hardness testing machine. A sample of $20 \mathrm{~mm}$ length was placed on the platform of the machine and needle was allowed to penetrate the sample till the failure of the sample. Impact strength was tested by IZODE METHOD on impact testing machine. Sample of length $50 \mathrm{~mm}$ was placed in the cavity which covers the $20 \mathrm{~mm}$ of the sample and rest of $30 \mathrm{~mm}$ was tested for impact strength. 


\section{Results and Discussion}

\section{Mechanism of synthesis of urea-formaldehyde resin}

The detailed mechanism for the synthesis of urea-formaldehyde resin as developed in applied chemistry laboratory was explained earlier ${ }^{14}$.

\section{Mechanism of synthesis of urea-resorcinol-formaldehyde resin}

The detailed mechanism for the synthesis of resorcinol-formaldehyde resin as developed in applied chemistry laboratory was explained earlier ${ }^{15}$. When these two resins were synthesized collectively they form a compact three dimensional network which has higher mechanical strength than these two individual resins.

\section{Optimization of urea - formaldehyde resin}

\section{Tensile strength}

The load - extension curves of the different ratios of UF resin are shown in Figure 1(a). It has been observed that with the increasing amount of formaldehyde in the samples the tensile strength also increases. This could be due to the formation of two and three dimensional network which owes to the increased tensile strength. The maximum tensile strength is shown by ratio 1.0:2.5 $(106.125 \mathrm{~N})$ followed by 1.0:2.0 $(63.525 \mathrm{~N}), 1.0: 3.0$ $(50.626 \mathrm{~N}), 1.0: 1.5(34.3 \mathrm{~N})$ and $1.0: 1.0(10.15 \mathrm{~N})$ with the \%age extension of 1.6(1.0:1.0), 2.02(1.0:1.5), $4.92(1.0: 2.0), 5.6(1.0: 2.5)$ and 6.9(1.0:3.0).

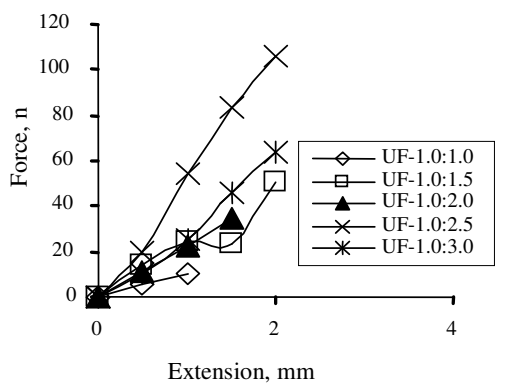

Figure 1(a). Tensile strength results of different ratios of UF resin

\section{Compressive strength}

The force versus compression curves of different ratios of UF resin are shown in Figure 1(b). It is observed from the curves that the UF ratio 1.0:2.5 have highest compressive strength of $987 \mathrm{~N}$ followed by 1.0:2.0(675 N), 1.0:1.5 $(370 \mathrm{~N}), 1.0: 3.0(289 \mathrm{~N})$ and 1.0:1.0 $(15.47 \mathrm{~N})$.

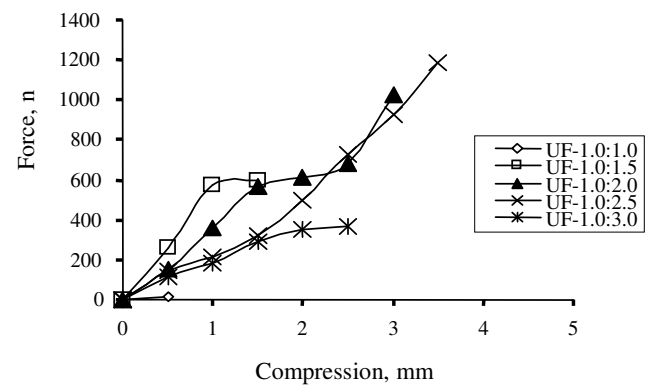

Figure 1(b). Compressive strength results of different ratios of UF resin 


\section{Flexural strength}

Similar trend has been observed for flexural strength results. The flexural properties of samples as a function of force and flexibility are shown in Table 1(a). The sample of ratio $1.0: 2.5$ show maximum flexural strength of $48.18 \mathrm{~N}$ and flexibility of $0.614 \mathrm{~mm}$.

Table 1(a). Values of various parameters from tensile strength curve for different ratios of UF resin

\begin{tabular}{cccccccc}
\hline $\begin{array}{c}\text { Sample } \\
\text { code }\end{array}$ & $\begin{array}{c}\text { Ultimate } \\
\text { stress }\end{array}$ & $\begin{array}{c}\text { Working } \\
\text { stress } \\
\mathrm{N}: \mathrm{F}\end{array}$ & $\begin{array}{c}\text { \%age } \\
\text { N/mm }\end{array}$ & $\begin{array}{c}\text { Yield } \\
\text { Elongation }\end{array}$ & $\begin{array}{c}\text { Fracture } \\
\text { stress } \\
\mathrm{N} / \mathrm{mm}^{2}\end{array}$ & $\begin{array}{c}\text { Standard } \\
\text { Neviation }\end{array}$ & $\begin{array}{c}\text { Tensile } \\
\text { modulus } \\
\text { N/mm }\end{array}$ \\
\hline $1.0: 1.0$ & 0.406 & 0.270 & 1.6 & 0.381 & 0.398 & 0.70 & 25.375 \\
$1.0: 1.5$ & 2.025 & 1.348 & 2.02 & 1.829 & 0.999 & 0.89 & 100.247 \\
$1.0: 2.0$ & 1.372 & 0.906 & 4.92 & 1.021 & 1.190 & 0.69 & 27.886 \\
$1.0: 2.5$ & 4.245 & 2.894 & 5.6 & 3.847 & 3.980 & 2.01 & 75.80 \\
$1.0: 3.0$ & 2.541 & 1.702 & 6.9 & 1.998 & 2.213 & 0.95 & 36.82 \\
\hline
\end{tabular}

\section{Hardness and impact strength}

The hardness and impact results are shown in Table 1(b).

Table 1(b). Values of impact strength, hardness, flexural strength/ flexibility and flexural modulus for different ratios of UF resin samples

\begin{tabular}{ccccc}
\hline $\begin{array}{c}\text { Sample } \\
\text { code U: F }\end{array}$ & $\begin{array}{c}\text { Impact strength } \\
\mathrm{kg}\end{array}$ & $\begin{array}{c}\text { Hardness } \\
\text { HRB }\end{array}$ & $\begin{array}{c}\text { Flexural strength(N)/ } \\
\text { Flexibility, mm }\end{array}$ & $\begin{array}{c}\text { Flexural modulus } \\
\text { N/mm }\end{array}$ \\
\hline $1.0: 1.0$ & 0.4 & 22 & $20.23 / 0.546$ & 88.92 \\
$1.0: 1.5$ & 0.4 & 34 & $24.56 / 0.623$ & 94.61 \\
$1.0: 2.0$ & 0.4 & 50 & $34.678 / 0.656$ & 126.84 \\
$1.0: 2.5$ & 0.5 & 56 & $48.18 / 0.678$ & 170.54 \\
$1.0: 3.0$ & 0.3 & 48 & $41.89 / 1.05$ & 95.74 \\
\hline
\end{tabular}

\section{Wear resistance}

It has been observed that wear rate of samples of ratio 1.0:2.5 was less as compared to any other samples as shown in Figure 1(c). Loss of material was due to abrasion and friction of samples with disc. The wear resistance results supports the tensile, compressive, flexural and hardness results, as brittle materials have higher wear rate and low tensile, compressive and flexural strength. The samples with lower amount of formaldehyde has higher concentration of dimethylol urea which makes it amorphous in nature but as the ratio of formalin increases the concentration of dimethylol urea decrease due to the formation of ether linkage and two three dimensional cross- linking.

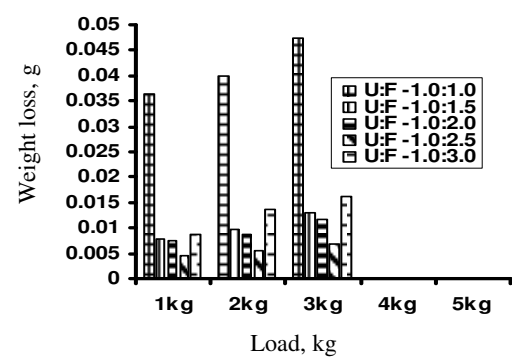

Figure 1(c). Wear strength results of different ratios of UF resin 
Samples of ratio 1.0:2.5 show maximum tensile, compressive, flexural strength and at this ratio wear rate was also very less. The hardness and impact strength of the samples of this ratio was found to be good as compared to other ratios. Therefore, this ratio was taken as optimized ratio for further preparation of urea resorcinol formaldehyde resin.

\section{Optimization of urea - resorcinol- formaldehyde resin}

\section{Tensile strength}

Tensile strength of U-R-F resin samples has been found to be high as compared to the samples of U-F resin as shown in Figure 2(a). Sample of ratio 1.0:1.0:2.5 show maximum tensile strength at a force of $555.75 \mathrm{~N}$ followed by $281.6 \mathrm{~N}(1.0: 0.5: 2.5), 95.2 \mathrm{~N}$ (1.0:1.5:2.5), $82.1 \mathrm{~N}(1.0: 2.0: 2.5)$ and $60.9 \mathrm{~N}(1.0: 2.5: 2.5)$. This could be due to the addition of resorcinol makes the structure compact which may owe to the increased tensile strength which is about 5 times greater than that of the UF resin sample.

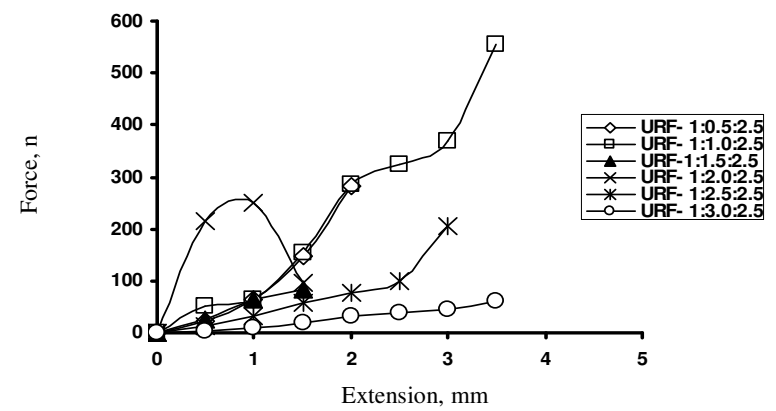

Figure 2(a). Tensile strength results of different ratios of URF resin

\section{Compressive strength}

Compressive strength of U- R- F samples is shown in Figure 2(b). URF resin with ratio: 1.0:1.0: 2.5 could bear maximum force of $1162 \mathrm{~N}$ which is about 1.2 times more than that of UF resin.

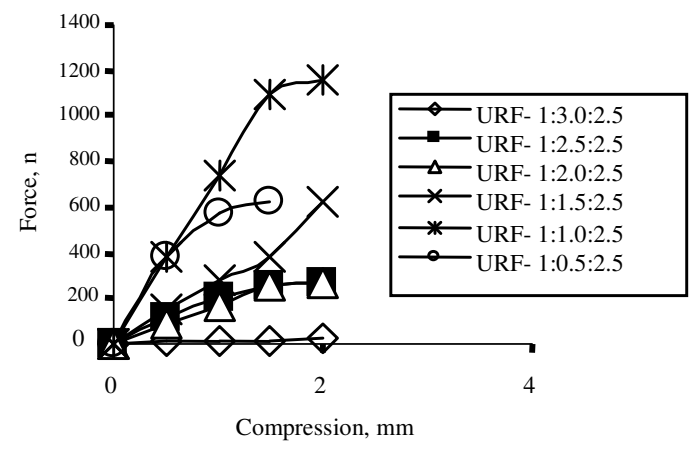

Figure 2(b). Compressive strength results of different ratios of URF resin

\section{Flexural strength}

As is evident from Table 2(a) that flexural strength and flexibility of URF resin samples is more as compared to UF samples. 
Table- 2(a) Values of various parameters from tensile strength curve for different ratios of URF resin

\begin{tabular}{cccccccc}
\hline $\begin{array}{c}\text { Sample } \\
\text { code }\end{array}$ & $\begin{array}{c}\text { Ultimate } \\
\text { stress } \\
\text { U:R:F }\end{array}$ & $\begin{array}{c}\text { Working } \\
\text { stress }\end{array}$ & $\begin{array}{c}\text { \%age } \\
\text { Elongation }\end{array}$ & $\begin{array}{c}\text { Yield } \\
\text { point } \\
\mathrm{N} / \mathrm{mm}^{2}\end{array}$ & $\begin{array}{c}\text { Fracture } \\
\text { stress } \\
\mathrm{N} / \mathrm{mm}^{2}\end{array}$ & $\begin{array}{c}\text { Standard } \\
\text { deviation }\end{array}$ & $\begin{array}{c}\text { Tensile } \\
\text { modulus } \\
\mathrm{N} / \mathrm{mm}^{2}\end{array}$ \\
\hline 1.0:0.5:2.5 & 11.264 & 7.921 & 7.23 & 9.249 & 10.109 & 1.28 & 155.79 \\
$1.0: 1.0: 2.5$ & 22.23 & 15.01 & 8.09 & 19.26 & 21.09 & 2.76 & 274.783 \\
$1.0: 1.5: 2.5$ & 7.284 & 4.678 & 8.56 & 5.982 & 6.70 & 0.98 & 85.09 \\
$1.0: 2.0: 2.5$ & 3.808 & 2.619 & 8.99 & 2.901 & 3.09 & 0.91 & 42.35 \\
$1.0: 2.5: 2.5$ & 8.2 & 5.346 & 10.79 & 6.42 & 7.45 & 1.79 & 76.066 \\
\hline
\end{tabular}

Wear test

Wear rate of U-R-F resin samples of all ratios has been found to be low as compared to U-F resin. The sample of ratio 1.0:1.0:2.5 exhibited less wear rate at all loads as compared to other samples as shown in Figure 2(c).

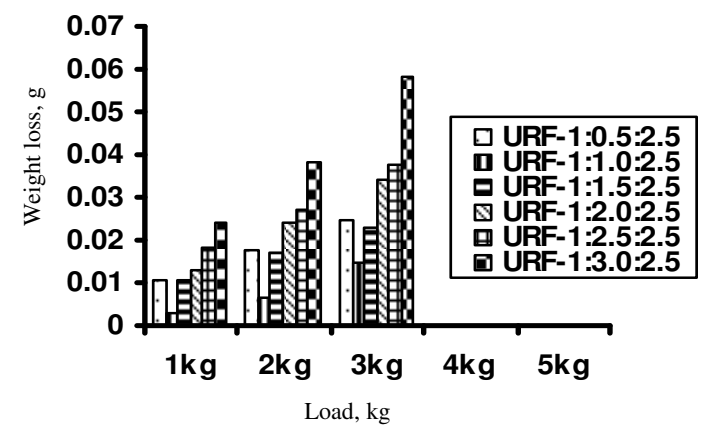

Figure 2(c). Wear strength results of different ratios of URF resin

\section{Hardness and impact strength}

Impact behavior of URF samples is more as compared to UF samples. URF samples have impact strength of $0.7 \mathrm{~kg}, 1.0 \mathrm{~kg}, 0.6 \mathrm{~kg}, 0.4 \mathrm{~kg}$ and $0.3 \mathrm{~kg}$ for 1.0:0.5:2.5, 1.0:1.0:2.5, 1.0:1.5:2.5, 1.0:2.0:2.5 and 1.0:2.5:2.5 respectively. Hardness values of URF samples are more as compared to UF samples. Hardness and impact results are shown in Table 2(b). Mechanical properties of U- R- F resin samples with ratio 1.0:1.0:2.5 were found good as compared to other samples. So, this ratio was taken further to prepare composites.

Table 2(b). Values of impact strength, hardness, flexural strength/ flexibility and flexural modulus for different ratios of URF resin samples

\begin{tabular}{ccccc}
\hline $\begin{array}{c}\text { Sample } \\
\text { code U:R:F }\end{array}$ & $\begin{array}{c}\text { Impact } \\
\text { strength kg }\end{array}$ & $\begin{array}{c}\text { Hardness } \\
\text { HRB }\end{array}$ & $\begin{array}{c}\text { Flexural strength(N)/ } \\
\text { Flexibility, mm }\end{array}$ & $\begin{array}{c}\text { Flexural modulus } \\
\text { N/mm }\end{array}$ \\
\hline $1.0: 0.5: 2.5$ & 0.7 & 45 & $51.78 / 0.789$ & 157.50 \\
$1.0: 1.0: 2.5$ & 1.0 & 67 & $63.24 / 0.856$ & 177.30 \\
$1.0: 1.5: 2.5$ & 0.6 & 56 & $56.78 / 0.889$ & 153.28 \\
$1.0: 2.0: 2.5$ & 0.4 & 50 & $45.34 / 0.785$ & 138.61 \\
$1.0: 2.5: 2.5$ & 0.3 & 34 & $21.89 / 1.09$ & 48.19 \\
\hline
\end{tabular}




\section{Effect of reinforcement on the mechanical properties of $U-R-F$ based composites}

Table 3 (b) shows the rockwell hardness measurements of URF samples loaded with pine needles. URF samples at the fiber content of $30 \%$ show highest hardness followed by $40 \%$, $20 \%, 10 \%$ and $50 \%$ fiber contents. An increase in hardness is evident as the content of filler increases. This could be due to the fact that lignocellulosic fillers display considerably higher hardness than that of the brittle matrix. But at the higher filler content the low hardness values may be due to poor adhesion of matrix and filler as the filler content is more. The hardness results are supported by wear resistance, since hard materials better resist friction and wear.

Figure 3(c) shows the wear resistance of URF composites reinforced with pine needles. It is evident from the figure that wear resistance increases as the fiber content increases from $10 \%$ to $30 \%$ but after this wear resistance decreases due to lack of adhesion between polymer matrix and fibers. As the load was increased from $1 \mathrm{~kg}$ to $3 \mathrm{~kg}$ the wear resistance decreases due to increase in friction between the disc and sample surface.

The tensile properties of the composites as the function of load and extension are presented in Figure 3(a). From the graph it is evident that first tensile force increases with the increase in fiber content but after $30 \%$ fiber content a significant decrease in tensile strength is observed. The tensile strength is higher for URF composites with fiber content $30 \%$ and after this decrease is almost proportional to filler content. Similar behavior is observed for \%age elongation which increases with the increase in fiber content and brittleness decreases.

The possible reasons proposed for poor tensile strength of composites is lack of adhesion of fibers and matrix, as the fibers cling together in bundles inhibiting the dispersion of individual fibers. From the curves in Figure 3(a) it has been observed that there is a significant change in the fracture mode the specimens reinforced with the pine needles in comparison with the unfilled URF matrix. The fracture becomes more ductile due to the presence of the reinforcing fiber, a material much elastic than the brittle polymer matrix.

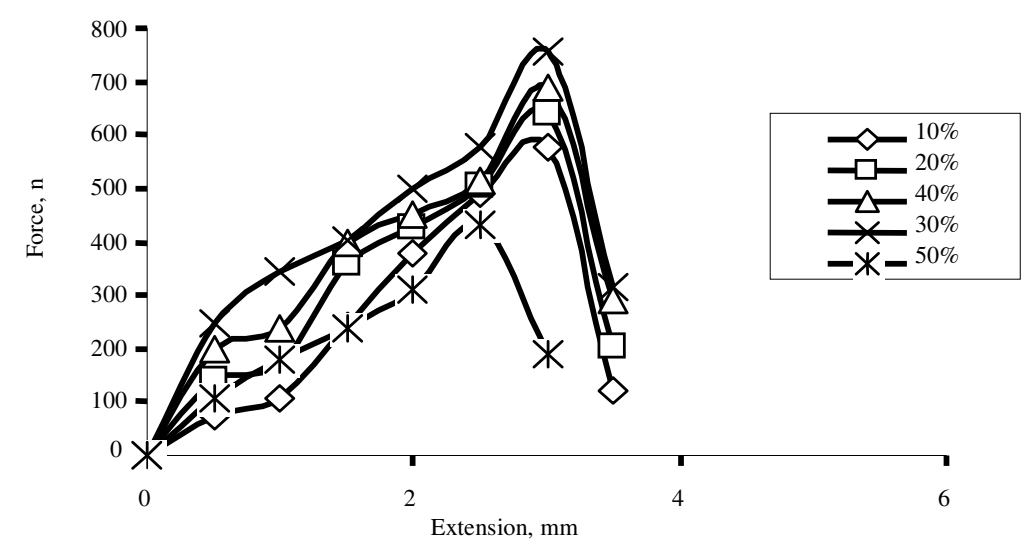

Figure 3(a). Tensile strength results of pine needles reinforced URF resin

Similar behavior is observed in force versus compression curves Figure 3(b). With increase in fiber content compressive force also increases. Flexural strength of the filled matrix is more as compared to the unfilled matrix as shown in Table 3(a). The impact strength of the loaded and unloaded matrix is presented in Table 3(b). 


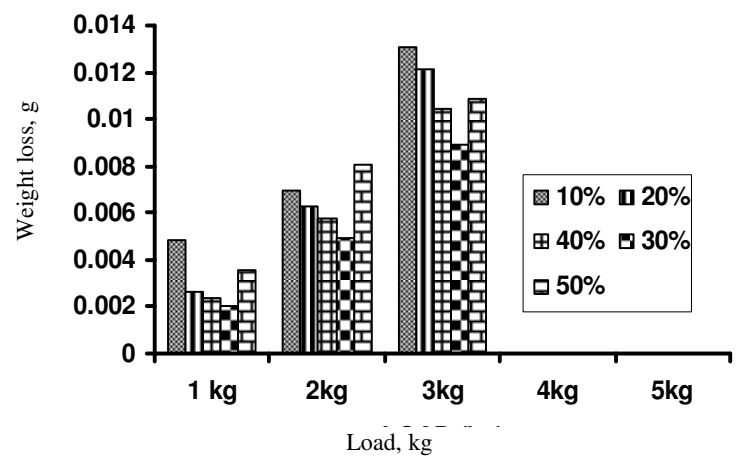

Figure 3(b). Wear resistance results of pine needles reinforced URF resin

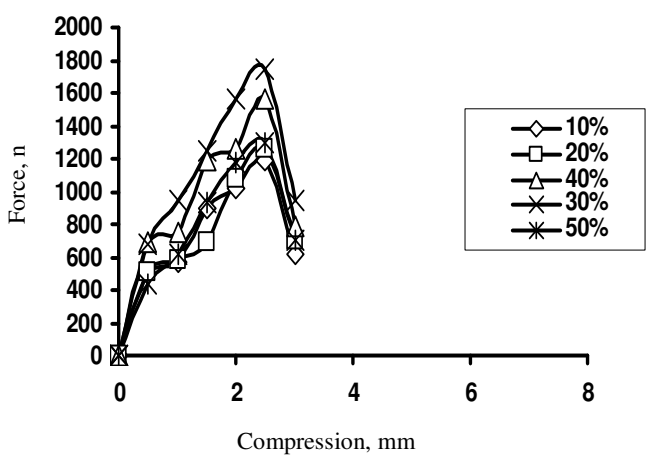

Figure 3(c). Compressive strength results of Pine needles reinforced URF resin

Table 3(a). Values of various Parameters from tensile strength curve for different \%age reinforcement

\begin{tabular}{cccccccc}
\hline $\begin{array}{c}\text { Fiber } \\
\text { content }\end{array}$ & $\begin{array}{c}\text { Ultimate } \\
\text { stress } \\
\mathrm{N} / \mathrm{mm}^{2}\end{array}$ & $\begin{array}{c}\text { Working } \\
\text { stress } \\
\mathrm{N} / \mathrm{mm}^{2}\end{array}$ & $\begin{array}{c}\text { \%age } \\
\text { Elongation }\end{array}$ & $\begin{array}{c}\text { Yield } \\
\text { point } \\
\mathrm{N} / \mathrm{mm}^{2}\end{array}$ & $\begin{array}{c}\text { Fracture } \\
\text { stress } \\
\mathrm{N} / \mathrm{mm}^{2}\end{array}$ & $\begin{array}{c}\text { Standard } \\
\text { deviation }\end{array}$ & $\begin{array}{c}\text { Tensile } \\
\text { modulus } \\
\mathrm{N} / \mathrm{mm}^{2}\end{array}$ \\
\hline $10 \%$ & 23.1 & 15.21 & 14.46 & 19.56 & 20.21 & 1.62 & 159.75 \\
$20 \%$ & 25.52 & 17.12 & 15.29 & 20.12 & 21.49 & 1.54 & 166.91 \\
$30 \%$ & 30.23 & 19.95 & 15.98 & 23.12 & 24.71 & 2.01 & 189.174 \\
$40 \%$ & 27.56 & 18.04 & 14.29 & 20.52 & 23.46 & 2.71 & 192.86 \\
$50 \%$ & 17.2 & 12.092 & 13.98 & 14.96 & 15.96 & 1.98 & 123.032 \\
\hline
\end{tabular}

Table 3(b). Values of impact strength, hardness, flexural strength/ flexibility and flexural modulus for different ratios of UF resin samples

\begin{tabular}{ccccc}
\hline $\begin{array}{c}\text { Sample } \\
\text { code }\end{array}$ & $\begin{array}{c}\text { Impact strength } \\
\mathrm{kg}\end{array}$ & $\begin{array}{c}\text { Hardness } \\
\text { HRB }\end{array}$ & $\begin{array}{c}\text { Flexural strength(N)/ } \\
\text { Flexibility, mm }\end{array}$ & $\begin{array}{c}\text { Flexural modulus } \\
\mathrm{N} / \mathrm{mm}^{2}\end{array}$ \\
\hline $10 \%$ & 1.0 & 68 & $76.89 / 0.998$ & 184.90 \\
$20 \%$ & 1.4 & 75 & $112 / 1.02$ & 263.52 \\
$30 \%$ & 1.8 & 89 & $167 / 1.23$ & 325.85 \\
$40 \%$ & 1.2 & 78 & $154 / 1.47$ & 251.42 \\
$50 \%$ & 0.8 & 69 & $123 / 1.78$ & 165.84 \\
\hline
\end{tabular}


From the tensile/compressive strength curves stress-strain curves were plotted and various parameters such as ultimate stress, yield strength, fracture strength, working stress and tensile, compressive and flexural modulii were calculated and presented in Table 1(a), 1(b), 2(a), 2(b), 3(a) and 3(b) for UF, URF and URF reinforced with pine needles respectively.

From the results it is clear that interfacial bond between matrix and the cellulosic fiber is the most essential factor for achieving good mechanical strength. During the loading, loads are not directly applied to the fibers but to the matrix and it is the interfacial bond between the matrix and the fiber which transfers the load to the fiber. Poor adhesion between the matrix and fiber leads to poor mechanical strength. In the present case the adhesion is due to the formation of hydrogen bonds between the hydroxyl groups of the fibers to the free methylol groups on the matrix. This has been obtained by good fiber dispersion in the polymer matrix. Good fiber dispersion implies that the fibers are separated from each other (i. e. there are no clumps and agglomerates) and each fiber is surrounded by the matrix. In the composites with low fiber loading there is more resin-rich areas which are weak and results in low mechanical strength of the composites and in case of higher fiber loading there are more fiber rich areas which are susceptible to micro cracking thus results in low mechanical strength. Mechanical properties of composites have been increase many times as compared to the unloaded matrix.

\section{Morphological and thermal behavior}

SEM micrographs of UF, URF and URF-SFrnf are shown in Figure 4(a), 4(b) and 4(c) respectively. These micrographs show the clear cut difference in the morphology of the resin and it's composite.

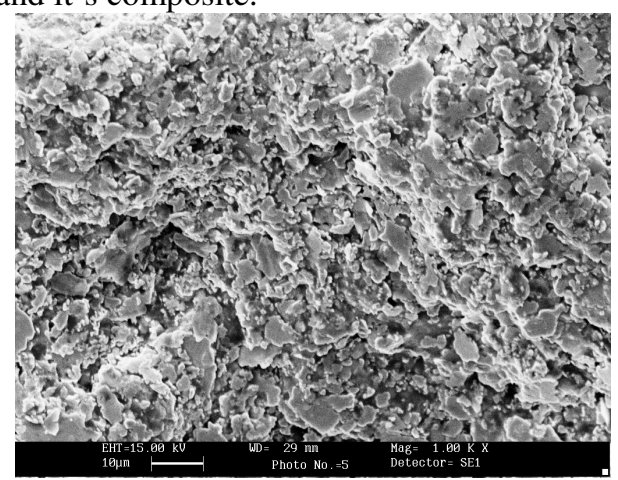

Figure 4(a). SEM micrograph of UF resin

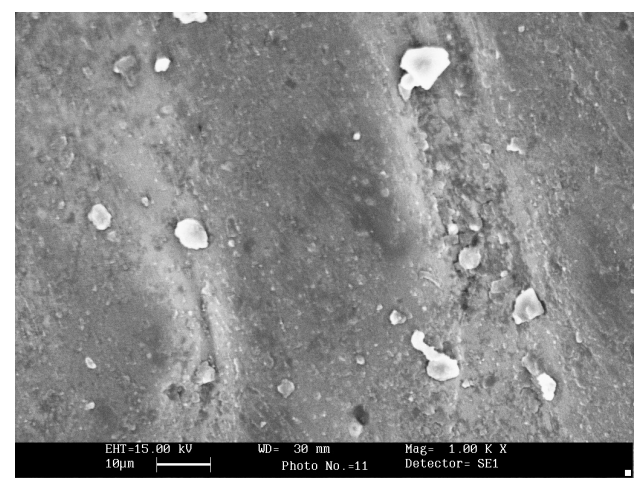

Figure 4(b). SEM micrograph of URF resin

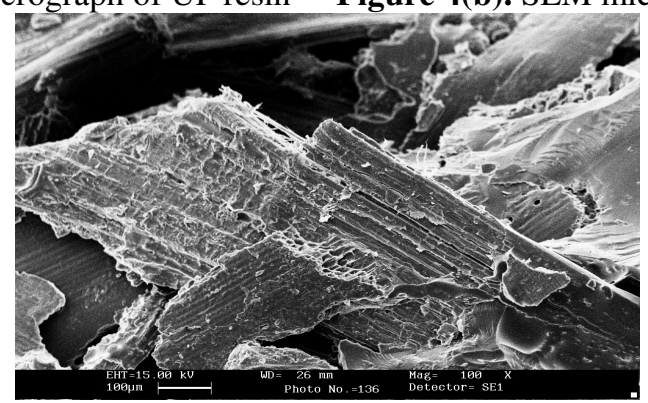

Figure 4(c). SEM micrograph of pine needles reinforced URF resin 
Thermogravimetric analysis (TGA) and differential thermogravimetric analysis (DTA) of UF, URF, URF-SFrnf and raw fiber are shown in Tables 4(a) and 4(b). The values of composite are in between the degradation temperatures for polymeric matrix (URF) and raw fiber. This indicates that the presence of cellulosic fiber affects the degradation process of the composites. These results also support the mechanical results of the samples as URF resin has higher decomposition temperature as compared to UF resin. These were consistent with the results reported earlier ${ }^{4,15}$.

Table 4(a). Thermogravimetric analysis of UF, URF, PN an URF-SFrnf composites

\begin{tabular}{ccccccc}
\hline $\begin{array}{c}\text { S. } \\
\text { No. }\end{array}$ & $\begin{array}{c}\text { Sample } \\
\text { code }\end{array}$ & $\begin{array}{c}\text { IDT } \\
{ }^{\circ} \mathrm{C}\end{array}$ & $\begin{array}{c}\text { \%Weight } \\
\text { loss }\end{array}$ & $\begin{array}{c}\text { FDT } \\
{ }^{\circ} \mathrm{C}\end{array}$ & $\begin{array}{c}\text { \% Weight } \\
\text { loss }\end{array}$ & $\begin{array}{c}\text { Final } \\
\text { residue }\end{array}$ \\
\hline 1. & UF & 238 & 22.48 & 990 & 67.51 & 32.49 \\
2. & URF & 305 & 20.67 & 996 & 69.2 & 30.8 \\
3. & PN & 223 & 23.45 & 507 & 84.44 & 15.66 \\
4. & URF-SFrnf & 289 & 13.57 & 904 & 74.68 & 25.32 \\
\hline
\end{tabular}

Table 4(b). Differential thermal analysis of UF, URF, PN an URF-SFrnf composites

\begin{tabular}{ccl}
\hline S. No. & Sample Code & Exothermic/ Endothermic peaks ${ }^{\circ} \mathrm{C}, \mu \mathrm{V}$ \\
\hline 1. & $\mathrm{UF}$ & $179[6.8], 253[5.7], 271[27.9], 545[9.4] ; 725[-23.0]$ \\
2. & URF & $65[-1.0], 278[8.0], 389[6.0]$ \\
3. & PN & $333.2[10.3], 478[29.9]$ \\
4. & URF-SFrnf & $198[-11.7], 234[7.9]$ \\
\hline
\end{tabular}

\section{Conclusion}

In case of mechanical behavior urea formaldehyde resin show lower mechanical properties which has been improved by mixing resorcinol in this resin. This could be due to strong bonding in URF resin as compared to UF resin. The mechanical properties of pine needles reinforced PRF composites have been investigated as a function of chemical nature of matrix and content of fiber in the composite. Pine needles have the potential ability to work as the good reinforcing agent in the polymer matrices. The mechanical properties of pine needles reinforced matrix are higher than as compared to unloaded matrix. Secondly pine needles have the potential to substitute synthetic fibers for the synthesis of green and ecofriendly composites. These composites can be the future material for the fabrication of environment-friendly materials. The mechanical behavior has been strongly supported by the SEM and thermal studies.

\section{Acknowledgment}

We express our sincere thanks to Director, National Institute of Technology (Deemed Universiy), Hamirpur for providing the basic laboratory facilities. We are also thankful to Dr. Rakesh Sehgal Department of Mechanical Engineering for their assistance and help in conducting mechanical studies. We are thankful to UGC (Delhi) for providing financial assistance grant No. F. NO. - 30-80/2004(SR) to carry out the research work.

\section{References}

1. Bledzki A K, Izbicka J and Gassan J, Kunststoffe - Umwelt - Recycling, Stettin [Poland], 1995, September 27-29. 
2. Nabi Saheb D and Jog J P, Adv Polym Technol., 1999, 18(4), 351-63.

3. Singha A S, Anjali Shama and Mishra B N, J Polym Mater., 2008, 25(1), 91-99.

4. Singha A S, Kumar S and Kaith B S, Int J Plast Technol., 2005, 9, 427.

5. Singha A S, Kaith B S and Sarwade B D, Hungarian J Ind Chem VESZPREM, 2002, 30, 289-293.

6. $\quad$ Kohler R and Wedler M, Landinfo, 1995, 3, 33-38.

7. Mieck K P, Ncchwatal A and Knobelsdorf C, Melliand Textiberichte, 1994, 11, 892-898.

8. $\quad$ Mieck K P and Reubmann T, Kunststoffe, 1995, 85(3), 366-370.

9. Mukherjee P S and Satyanarayana K G, J Mat Sci., 1986, 21, 51-56.

10. Kaith B S, Singha A S, Dwedi D K, Sanjeev Kumar, Kumar D and Dhemeniya A, Int J Plast Technol., 2003, 7, 119-125.

11. Kaith B S, Singha A S, Dwedi D K, Sanjeev Kumar, Kumar D and Dhemeniya A, Int J Plast Technol., 2004, 8(2), 299-304.

12. Wittig W, Kunststoffe im Automobilbau, VDI- Verlag, DUSSELDORF, 1994.

13. Singha A S, Anjali Shama and Vijay Kumar Thakur, Bull Mat Sci., 2008, 31(1), 07-013.

14. Singha A S and Vijay Kumar Thakur, E- J Chem., 2008, 5(4), 782-791.

15. Singha A S and Vijay Kumar Thakur, E-J Chem., 2008, 5(S 1), 1055-1062. 


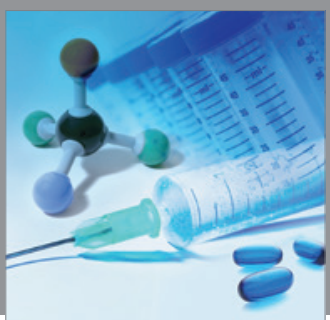

International Journal of

Medicinal Chemistry

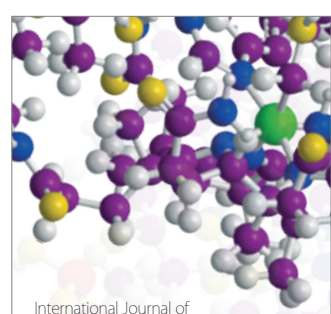

Carbohydrate Chemistry

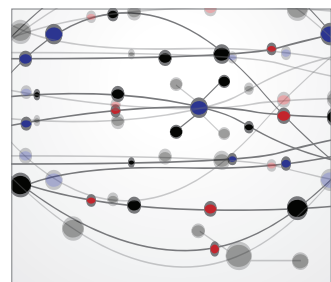

The Scientific World Journal
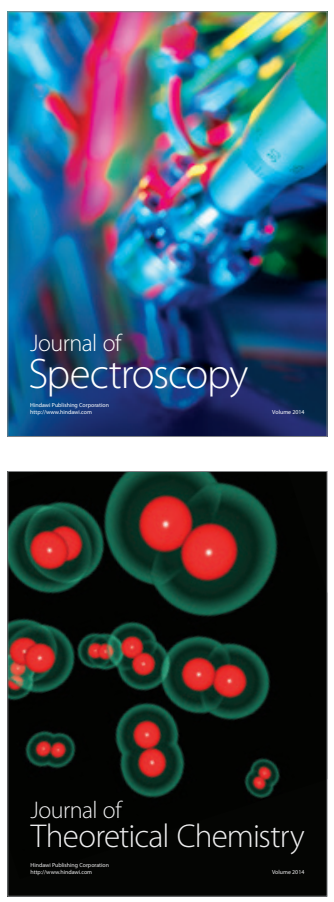
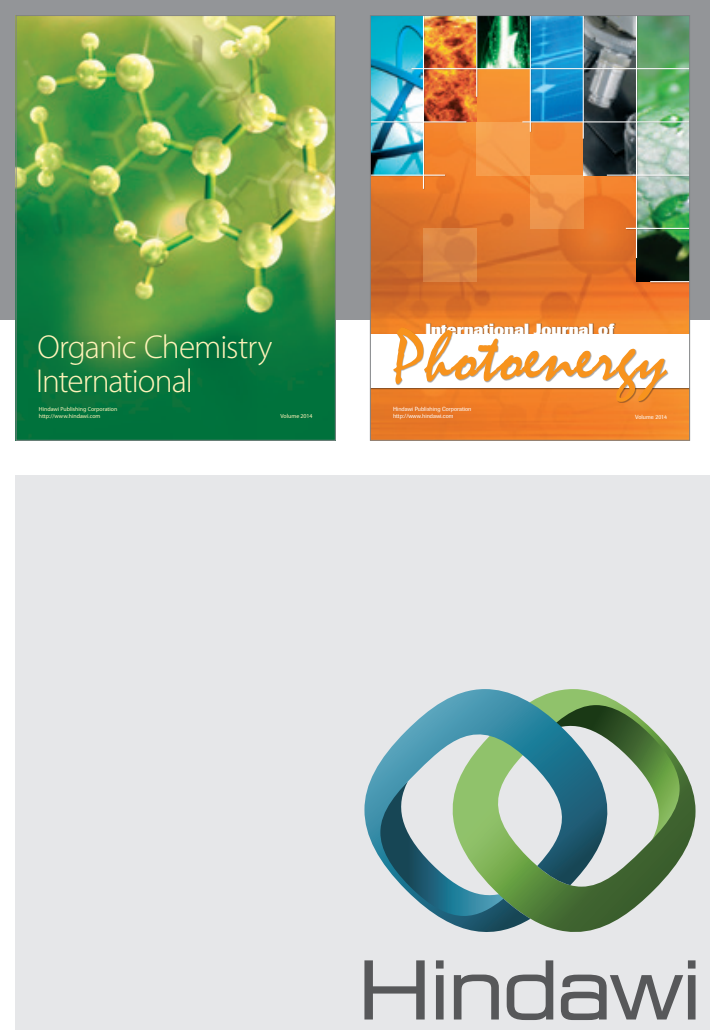

Submit your manuscripts at

http://www.hindawi.com
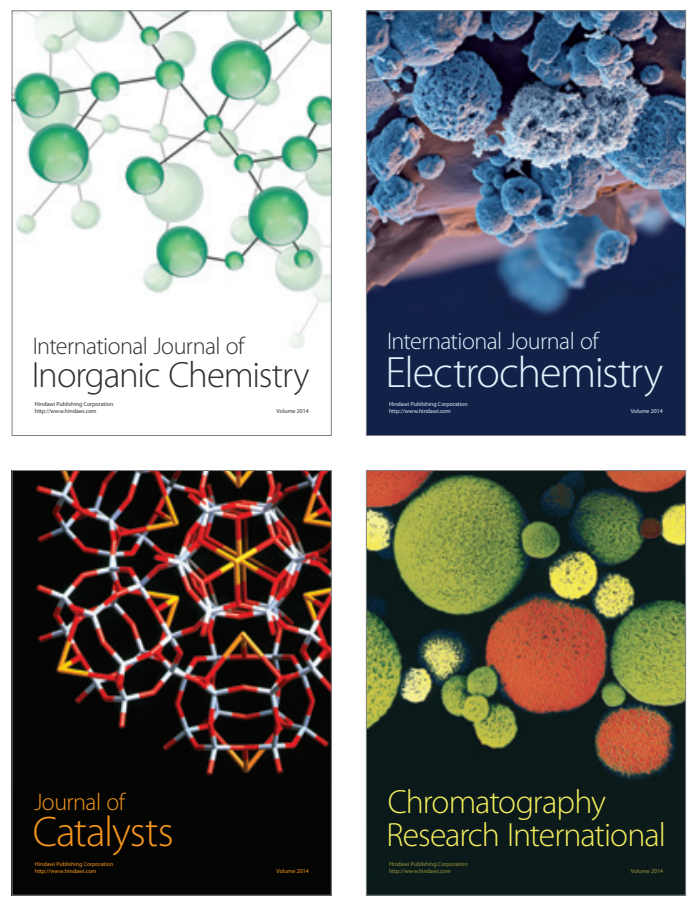
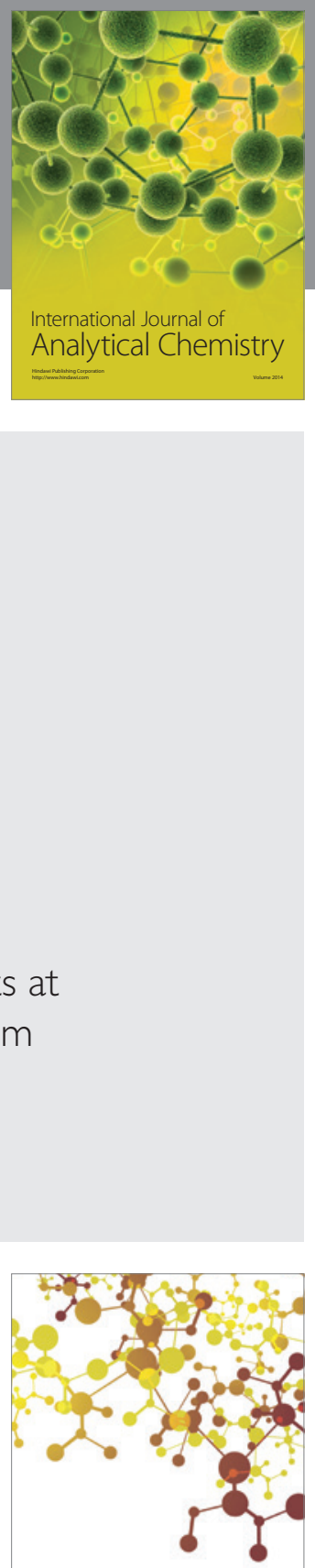

Journal of

Applied Chemistry
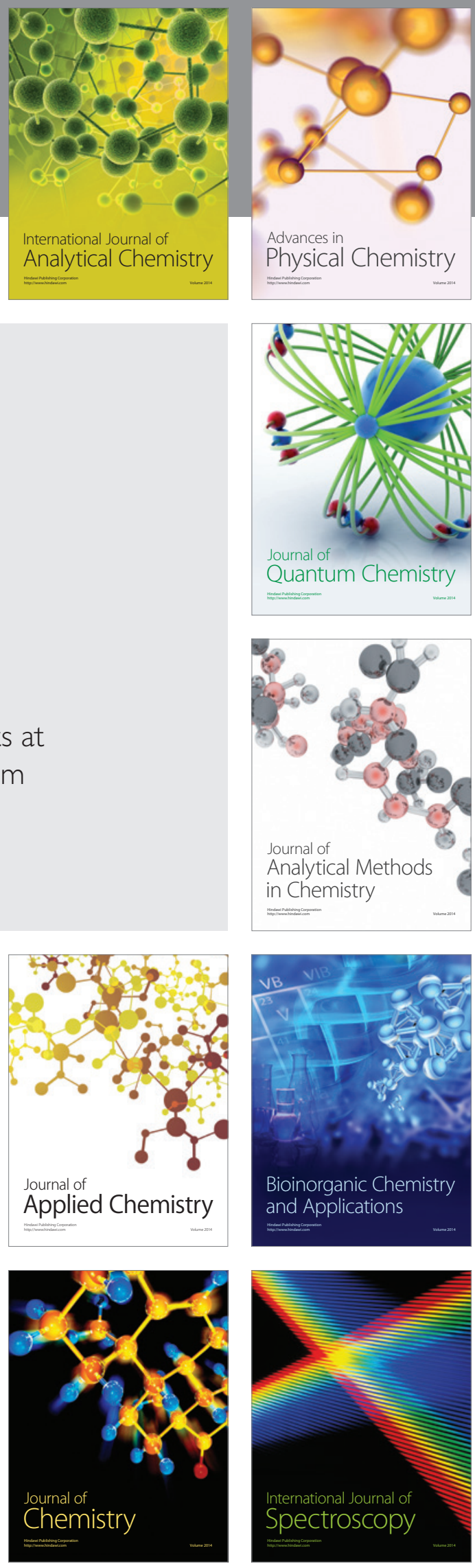